\title{
Increasing sexually transmitted infection rates in young men having sex with men in the Netherlands, 2006-2012
}

Femke DH Koedijk ${ }^{1,2}$, Birgit HB van Benthem ${ }^{1 *}$, Eliane MDC Vrolings ${ }^{3}$, Wim Zuilhof ${ }^{3}$ and Marianne $A B$ van der Sande $e^{1,4}$

\begin{abstract}
Background: Men having sex with men (MSM) remain the largest high-risk group involved in on-going transmission of sexually transmitted infections (STI), including HIV, in the Netherlands. As risk behaviour may change with age, it is important to explore potential heterogeneity in risks by age. To improve our understanding of this epidemic, we analysed the prevalence of and risk factors for selected STI in MSM attending STI clinics in the Netherlands by age group.

Methods: Analysis of data from the national STI surveillance system for the period 2006-2012. Selected STI were chlamydia, gonorrhoea, infectious syphilis and/or a new HIV infection. Logistic regression was used to identify factors associated with these selected STI and with overall STI positivity. Analyses were done separately for MSM aged younger than 25 years and MSM aged 25 years and older.

Results: In young MSM a significant increase in positivity rate was seen over time $(p<0.01)$, mainly driven by increasing gonorrhoea diagnoses, while in MSM aged 25 and older a significant decrease was observed $(p<0.01)$. In multivariate analyses for young MSM, those who were involved in commercial sex were at higher risk (OR: 1.5, 95\% Cl: 1.2-1.9). For MSM aged 25 years and older this was not the case. Having a previous negative HIV test was protective among older MSM compared to those not tested for HIV before (OR: 0.8, 95\% Cl: 0.8-0.8), but not among younger MSM.

Conclusions: MSM visiting STI clinics remain a high-risk group for STI infections and transmission, but are not a homogenous group. While in MSM aged older than 25 years, STI positivity rate is decreasing, positivity rate in young MSM increased over time. Therefore specific attention needs to be paid towards targeted counselling and reaching particular MSM sub-groups, taken into account different behavioural profiles.
\end{abstract}

Keywords: Commercial sex, Adolescents, Gay men, Epidemiology, Surveillance, Ethnicity

\section{Background}

Half of all new sexually transmitted infections (STI) occurs among young people aged 15-24 years [1,2]. High-risk groups drive STI transmission, with men having sex with men (MSM) being the largest single high-risk group in many industrialised countries. MSM are estimated to represent $5-9 \%$ of the male population in the Netherlands [3], and are responsible for $40 \%$ of consultations in men at Dutch STI clinics [1].

\footnotetext{
* Correspondence: birgit.van.benthem@rivm.nl

${ }^{1}$ Centre for Infectious Disease Control, RIVM National Institute of Public Health and the Environment, P.O. Box 1, 3720 BA Bilthoven, Utrecht, The Netherlands

Full list of author information is available at the end of the article
}

Young MSM are of special public health importance for STI and Human Immunodeficiency Virus (HIV) prevention worldwide. Young MSM often report participation in high-risk sexual behaviour and considerable numbers of HIV infections have been observed in several studies [4-6]. A recent European study showed that in the last decade, the largest increase of new HIV infections has been seen among young MSM [7]. Young MSM are at significantly greater risk of HIV seroconversion than older MSM [8]. Risk behaviour may have increased due to treatment optimism $[9,10]$, which can partly offset the gains made with safe sex campaigns. A recent Dutch study [11] showed that young MSM visiting STI clinics were at higher risk for both a single STI infection and STI 
co-infections than older MSM. However, that study did not go into detail about specific risk factors for young and older MSM. Here we analyse trends in different STI and HIV prevalence among MSM visiting STI clinics of two age-groups (MSM aged under 25 years and MSM aged 25 years and older), focusing on underlying risk factors and risk behaviour. The results can be used to guide targeted control strategies.

\section{Methods}

Since 2006, 26 dedicated STI clinics, mostly within the municipal public health services and some of them with additional outside test locations, provide anonymous low threshold STI/HIV testing and care, which is free of charge and targeted at high-risk groups [1]. This system of test and treat with follow up care was set up in addition to the regular national health services, to reach people who might otherwise not seek STI care timely. Persons matching one of the following criteria are considered to be at high-risk of STI acquisition: (1) reporting STI-related symptoms, (2) notified or referred for STI testing, (3) aged below 25 years, (4) men having sex with men (MSM), (5) involved in commercial sex, (6) originating from an HIV/STI endemic area, (7) reporting three or more sexual partners in the previous six months or (8) reporting a partner from one of these risk groups. All consultations and corresponding diagnoses are reported to the Centre for Infectious Disease Control (RIVM) for surveillance purposes, facilitated by a web based application (SOAP). The unit of analysis is 'new STI consultation', which is defined as a consultation for new symptoms or one resulting from routine STI screening of asymptomatic cases, both involving laboratory testing and medical examination. At each consultation, information on demographics (gender, year of birth, ethnicity), behaviour (STI history, commercial sex work (CSW)), diagnostics and clinical outcome is recorded by the clinician. All visitors were asked whether they had sex with men, women or both in the past six months. In this study, an MSM was defined as a men who reported to have had sex with men (and women) in the past six months. All clients are tested for chlamydia, gonorrhoea and syphilis and since 2010 an opt-out policy for HIV testing has been implemented. Other STI are tested on indication. Microbiological diagnostics are carried out locally at laboratories related to the STI clinics in accordance with standard procedures established in an STI screening protocol [12], including quality control measures.

\section{Statistical analyses}

For each STI (chlamydia, gonorrhoea, syphilis and HIV) the positivity rate was calculated by dividing the number of infections by the number of tests performed for that specific STI. Overall STI positivity rate was calculated by dividing the number of consultations in which at least one STI was found, by the total number of consultations. The Chi-square test was used for testing differences in proportions and trends in STI prevalence were determined using the Chi-square test for trend. A p-value $<0.05$ was considered to be significant. Univariate regression analyses were performed to identify factors associated with an infection. Factors associated with an STI with a p-value $<0.20$ were further analysed by backward multivariate logistic regression. In the multivariable model, variables with $p<0.01$ were considered statistically significant. Analyses were performed per STI and also for the overall risk on an STI. Analyses were split up by age group: younger than 25 years and 25 years or older. Known HIV positive MSM were excluded from the analyses, since they are known to have a very different risk profile. Analyses were carried out using the SAS software version 9.2.

\section{Results}

\section{Characteristics}

Between 2006 and 2012, 99,105 new STI consultations in MSM were registered in the national database at the RIVM. Of these, $17 \%(n=16,603)$ were in MSM younger than 25 years of age (Table 1) and $83 \%$ was 25 years and older. The number of consultations in MSM visiting an STI clinic increased steadily since 2006 (Figure 1). The number of consultations in MSM aged under 25 increased with $218 \%$ from 1,191 in 2006 to 3,791 in 2012; this increase was $114 \%$ in those aged 25 and older; from 7,761 in 2006 to 16,633 in 2012.

As shown in Table 1, MSM visiting STI clinics aged younger than 25 years reported more often having sex exclusively with other men, were less often of native Dutch, reported less often to be tested for HIV before, reported less often to have had a previous STI, reported more often to be involved in commercial sex work, were less often client of sex workers, reported less often to have had 10 or more sexual partners in the previous six months and reported less often STI symptoms than MSM aged 25 years or older (all $\mathrm{p}<0.01$ ). In both age groups, $12 \%$ reported to be notified for an STI.

\section{STI positivity rates}

The overall STI positivity rate was significantly higher in young MSM (15-24 years), compared to MSM aged 25 years or older; $18.6 \%$ versus $17.7 \%$; $(p<0.01)$. In both age groups, men having sex with men exclusively had a significantly higher STI positivity rate than men having sex with both men and women $(\mathrm{p}<0.01)$. In young MSM, positivity rate was highest in men originating from Latin America (30\%), in MSM aged 25 or older it was highest among MSM from Surinam and the Dutch Antilles and Sub-Sahara Africa (both 24\%). In both age groups, STI positivity rate was highest in those who 
Table 1 Socio-demographic and behavioural characteristics and STI (chlamydia, gonorrhoea, syphilis or HIV) positivity rate by age group in consultations in MSM visiting STI clinics, the Netherlands, 2006-2012

\begin{tabular}{|c|c|c|c|c|}
\hline \multirow[t]{2}{*}{ Characteristics } & \multicolumn{2}{|c|}{$15-24$ yrs ( $n=16,603 ;$ STI positivity $=18.6 \%$ ) } & \multicolumn{2}{|c|}{$\geq 25$ yrs $(\mathrm{n}=82,502 ; \mathrm{STI}$ positivity $=17.7 \%)$} \\
\hline & $\mathrm{N}(\%)$ & STI positivity (\%) & $\mathrm{N}(\%)$ & STI positivity (\%) \\
\hline \multicolumn{5}{|l|}{ Age, years } \\
\hline $15-19$ & $3023(18.2)$ & 16.4 & & \\
\hline $20-24$ & $13580(81.8)$ & 19.1 & & \\
\hline $25-34$ & & & $28550(34.6)$ & 19.5 \\
\hline $35-44$ & & & $26932(32.6)$ & 18.3 \\
\hline $45-54$ & & & $17871(21.7)$ & 16.5 \\
\hline$\geq 55$ & & & $9149(11.1)$ & 12.9 \\
\hline \multicolumn{5}{|l|}{ Sexual behaviour } \\
\hline Sex with both men and women & $2700(16.3)$ & 16.4 & $16391(19.9)$ & 12.9 \\
\hline Sex with men only & $13903(83.7)$ & 19.0 & $66111(80.1)$ & 18.9 \\
\hline \multicolumn{5}{|l|}{ Ethnicity } \\
\hline Dutch & $12657(76.2)$ & 17.0 & $64657(78.4)$ & 17.0 \\
\hline Surinam/Antilles & $854(5.1)$ & 28.3 & $2351(2.9)$ & 23.5 \\
\hline Turkey/Morocco & $373(2.3)$ & 19.6 & $1291(1.6)$ & 20.4 \\
\hline Eastern Europe & $486(2.9)$ & 27.6 & $1425(1.7)$ & 21.7 \\
\hline Sub-Sahara Africa & $167(1.0)$ & 23.4 & $449(0.5)$ & 24.3 \\
\hline Latin America & $359(2.2)$ & 29.8 & $1871(2.3)$ & 22.0 \\
\hline Asia & $551(3.3)$ & 18.5 & $2633(3.2)$ & 22.1 \\
\hline Other & $1156(7.0)$ & 20.9 & $7825(9.5)$ & 18.2 \\
\hline \multicolumn{5}{|l|}{ Previous HIV test } \\
\hline No & $6123(36.9)$ & 16.5 & $12785(15.5)$ & 18.8 \\
\hline Yes & $10043(60.5)$ & 20.0 & $67622(82.0)$ & 17.6 \\
\hline Unknown & $437(2.6)$ & 13.7 & $2095(2.5)$ & 16.2 \\
\hline \multicolumn{5}{|l|}{ Previous STI } \\
\hline No & $12618(76.0)$ & 17.4 & $60215(73.0)$ & 16.1 \\
\hline Yes & 1915 (11.5) & 28.8 & $12150(14.7)$ & 24.9 \\
\hline Unknown & $2070(12.5)$ & 16.2 & $10137(12.3)$ & 18.6 \\
\hline \multicolumn{5}{|l|}{ Csw } \\
\hline No & $15822(95.3)$ & 18.3 & $80153(97.2)$ & 17.8 \\
\hline Yes, in past 6 months & $592(3.6)$ & 29.7 & $1386(1.7)$ & 16.9 \\
\hline Unknown & $189(1.1)$ & 7.4 & $962(1.2)$ & 10.3 \\
\hline \multicolumn{5}{|l|}{ Client of CSW } \\
\hline No & $16281(98.1)$ & 18.7 & $79640(96.5)$ & 18.0 \\
\hline Yes, in past 6 months & $149(0.9)$ & 18.8 & $1988(2.4)$ & 9.5 \\
\hline Unknown & $173(1.0)$ & 8.7 & $874(1.1)$ & 12.0 \\
\hline \multicolumn{5}{|l|}{$\mathrm{Nr}$ of partners in $<6$ months } \\
\hline $0-1$ & $2884(17.4)$ & 13.6 & $8342(10.1)$ & 12.9 \\
\hline $2-10$ & 9581 (57.7) & 18.9 & $40959(49.7)$ & 17.1 \\
\hline$>10$ & $992(6.0)$ & 31.1 & $10751(13.0)$ & 20.4 \\
\hline Unknown & 3146 (18.9) & 19.0 & $22450(27.2)$ & 19.4 \\
\hline
\end{tabular}


Table 1 Socio-demographic and behavioural characteristics and STI (chlamydia, gonorrhoea, syphilis or HIV) positivity rate by age group in consultations in MSM visiting STI clinics, the Netherlands, 2006-2012 (Continued)

\begin{tabular}{|c|c|c|c|c|}
\hline \multicolumn{5}{|l|}{ STI symptoms } \\
\hline No & $11134(67.1)$ & 14.9 & $50728(61.5)$ & 13.6 \\
\hline Yes & 3076 (18.5) & 34.0 & 17607 (21.3) & 28.7 \\
\hline Unknown & $2393(14.4)$ & 16.1 & $14167(17.2)$ & 19.0 \\
\hline \multicolumn{5}{|l|}{ Notified } \\
\hline No & $12239(73.7)$ & 16.2 & $58147(70.5)$ & 15.5 \\
\hline Yes & 1992 (12.0) & 36.0 & 9764 (11.8) & 29.0 \\
\hline Unknown & $2372(14.3)$ & 16.3 & $14591(17.7)$ & 19.4 \\
\hline \multicolumn{5}{|l|}{ STI positivity } \\
\hline Chlamydia & $1627(9.9)$ & - & $7292(8.9)$ & \\
\hline Gonorrhoea & $1465(9.0)$ & - & $6078(7.5)$ & \\
\hline Infectious syphilis & $272(1.7)$ & - & $1867(2.3)$ & \\
\hline HIV & $246(1.5)$ & - & $1778(2.4)$ & \\
\hline
\end{tabular}

reported a previous STI in the past two years, multiple sex partners, STI symptoms and to be notified by a partner for an STI. Positivity rate in MSM under 25 years of age who were involved in CSW was $30 \%$, which was significantly higher than in MSM of 25 years and older involved in CSW (17\%; p < 0.01). Positivity rates for chlamydia and gonorrhoea were significantly higher in MSM younger than 25 years compared MSM aged 25 years and older, while syphilis and HIV positivity rates were higher in MSM aged 25 years and older (all p < 0.01).

\section{Time trends in positivity rates by age group}

As shown in Figure 2, an increasing trend in STI positivity over time was observed in MSM younger than 25 years; from $17 \%$ and $16 \%$ in 2006 and 2007 to $21 \%$ in 2011 and $19 \%$ in 2012 ( $\mathrm{p}<0.01)$. In MSM aged 25 years and older a significant decrease was seen: from $22 \%$ in 2006 to $17 \%$ in 2009 and subsequent years $(\mathrm{p}<0.01)$. The increasing positivity rate in young MSM was mainly caused by increasing positivity rates for gonorrhoea, which increased significantly from $8.4 \%$ in 2006 to $10.5 \%$ in 2012 ( $<<0.01$ ). In MSM aged 25 years and older, a significant decreasing trend in positivity rate was found for all STI except for chlamydia, which remained stable.

\section{Logistic regression analyses for young MSM}

Table 2 presents the results for multivariable logistic regression analyses for the characteristics associated with having at least one STI among MSM younger than 25 years. An additional file shows a table with the univariate analyses for any STI [see Additional file 1].

Young MSM who reported a previous STI or being notified for an STI were at higher risk on having a new STI compared to those who did not report this. Ethnicity was also associated with the risk of testing positive for STIs, but this differed per STI: for chlamydia only those from Suriname or the Dutch Antilles were at significant higher risk compared to young native Dutch MSM (OR 1.5; 95\% CI: 1.2-1.9), while for HIV almost all nonDutch young MSM were at higher risk. MSM younger than 25 years from Latin America were at significant higher risk for gonorrhoea (OR 1.8), syphilis (OR 3.1) and HIV (OR 4.5).

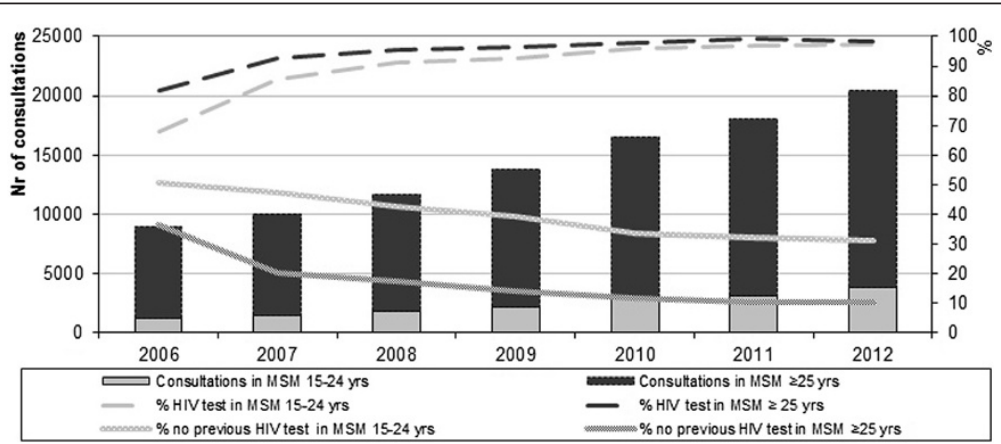

Figure 1 Trends in STI consultations and HIV test behaviour for MSM visiting STI clinics, by age group, the Netherlands, 2006-2012. 


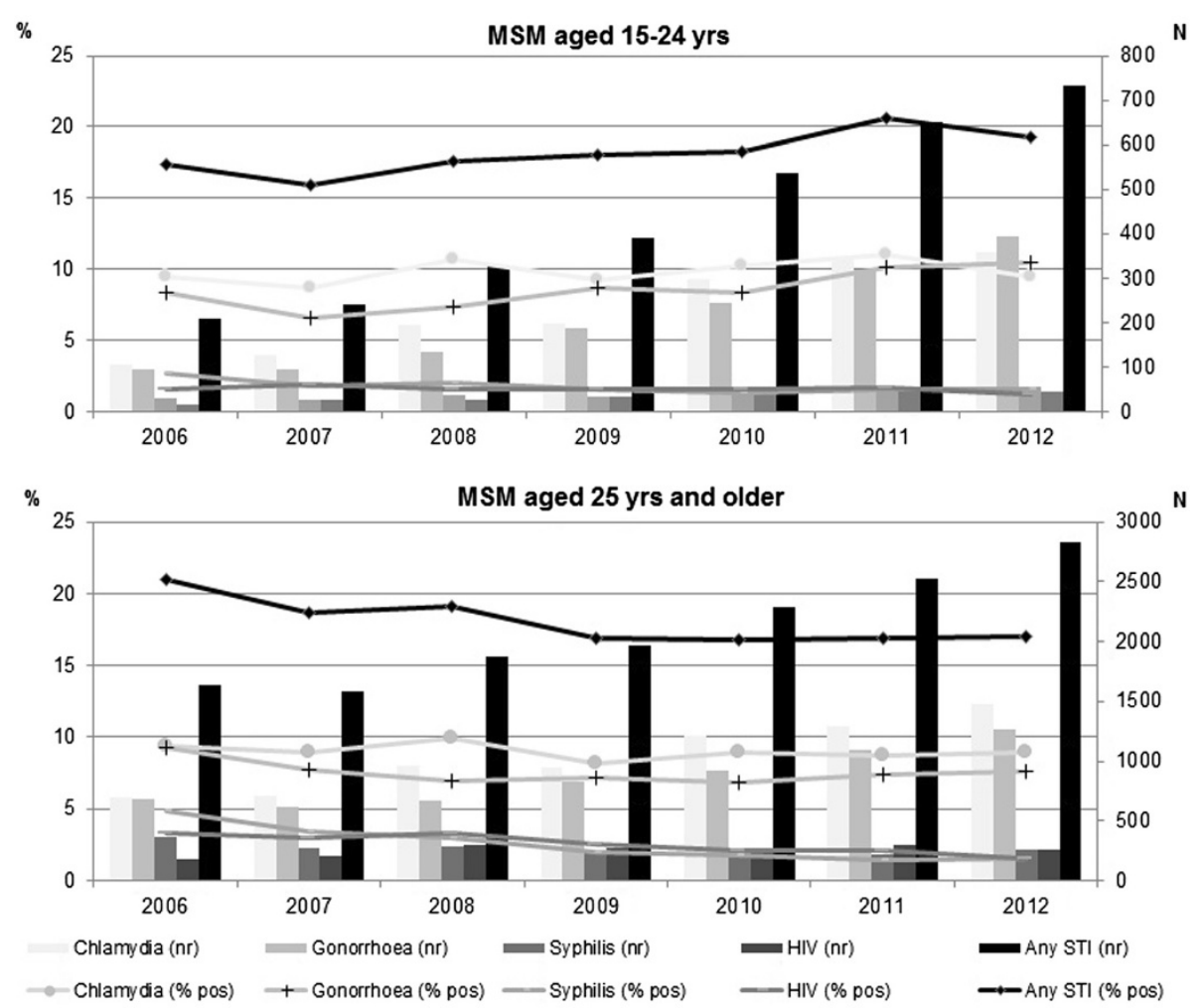

Figure 2 Trends in STI positivity rate (left axis) and number of STI (right axis) for different STI for MSM visiting STI clinics, by age group, the Netherlands, 2006-2012.

MSM younger than 25 years who reported to be involved in commercial sex work (CSW) were at significantly higher risk for chlamydia (OR 1.4), gonorrhoea (OR 1.5) and syphilis (OR 2.7) compared to those not involved in CSW. Furthermore, the number of sex partners was also significantly associated with increased risk for all STI except for syphilis.

\section{Logistic regression analyses for older MSM}

Table 3 is showing the results of the multivariate analyses for any STI and for all STI separately. In MSM aged 25 and older, having sex with men exclusively (overall OR 1.5), a previous STI (OR 1.7), and being notified for an STI (OR 2.2) were independent risk factors associated with all STI. An additional file shows a table with the univariate analyses for any STI [see Additional file 1]. Those MSM who had been tested negative for HIV at a previous visit to the STI clinic were at significantly lower risk than those not tested for HIV previously (OR 0.8). Similar with MSM younger than 25 years, older MSM clinic visitors from Suriname or the Dutch Antilles were at higher risk for all STI compared to Dutch MSM (overall OR 1.5). All non-Dutch MSM visitors, except those from Turkey or Morocco, were at higher risk for testing HIV positive compared to Dutch MSM, with those from Sub Saharan
Africa being at highest risk (OR 3.8). For chlamydia and gonorrhoea, risk on positivity decreased significantly with age, while risk on syphilis increased with age. As in young MSM, reporting an increasing number of sexual partners was significantly associated with risk on testing positive for all STI, except for syphilis.

\section{Discussion}

During 2006-2012, the number of STI consultations by MSM in Dutch STI clinics increased steadily in both age groups, whereby highest positivity rates and specific risks were observed for younger MSM. Of all MSM clinic visitors aged 15-24 years, 19\% tested positive for at least one STI, and this positivity rate increased significantly since 2007, driven by higher gonorrhoea positivity rates. Among MSM 25 years and older, overall positivity rate was $19 \%$, but decreased since 2006 and remained stable since 2009. Positivity rates for syphilis decreased in both young and older MSM, and in older MSM HIV positivity rate also decreased significantly. Specific ethnic groups were at higher risk for testing positive for any STI, as were those reporting exclusively having sex with men, those with a history of STI, those reporting having multiple sex partners and those notified for an STI. 
Table 2 Multivariate regression analyses for any STI and per STI in consultations in young MSM (<25 years) visiting STI clinics, the Netherlands, 2006-2012

\begin{tabular}{lrrrrr}
\hline & $\begin{array}{r}\text { Any STI } \\
\text { OR }(95 \% \mathrm{Cl})\end{array}$ & $\begin{array}{r}\text { Chlamydia } \\
\text { OR }(95 \% \mathrm{Cl})\end{array}$ & $\begin{array}{r}\text { Gonorrhoea } \\
\text { OR }(95 \% \mathrm{Cl})\end{array}$ & $\begin{array}{rrr}\text { Infectious syphilis } \\
\text { OR }(95 \% \mathrm{Cl})\end{array}$ & OR $(95 \% \mathrm{Cl})$ \\
\hline Year of consult & NS & NT & $1.1(1.0-1.1)$ & NS & NT
\end{tabular}

Age, years

15-19

20-24
NT

\section{Sexual behaviour}

Sex with both men and women

Sex with men only

Ethnicity

Dutch

Surinam/Antilles

Turkey/Morocco

Eastern Europe

SS Africa

Latin America

Asia

Other

Previous HIV test

No

Yes, negative

Unknown

Previous STI

No

Yes

Unknown

CSW

No

Yes, in $<6$ months

Unknown

\section{Client of CSW}

No

Yes, in $<6$ months

Unknown

No of partners in $<6$ months

0-1

2-10

$>10$

Unknown

Notified

No

Yes

Unknown

NS

1.0

$1.3(1.2-1.5)$

1.0

1.9 (1.6-2.2)

$1.2(0.9-1.6)$

$1.5(1.2-1.9)$

$1.5(1.1-2.2)$

1.9 (1.5-2.4)

$1.1(0.9-1.3)$

1.3 (1.1-1.5)

NS

NS

1.5 (1.2-1.9)

$0.9(0.6-1.3)$

$1.2(0.9-1.7)$

$1.3(0.8-2.1)$

$1.3(0.9-1.8)$

$0.9(0.7-1.2)$

$0.9(0.8-1.2)$

NT

$1.8(1.6-2.0)$

$1.0(0.9-1.2)$

1.5 (1.3-1.7)

$1.0(0.9-1.3)$

1.0

1.5 (1.2-1.9)

$0.4(0.2-0.7)$

1.4 (1.1-1.8)

$0.5(0.2-0.9)$

NS

NS
NS

NS

1.0

$1.8(1.1-2.7)$

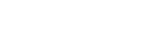

$1.6(1.4-1.9)$

1.0

$1.6(1.3-2.0)$

$1.2(0.8-1.7)$

$1.0(0.8-1.5)$

$1.3(0.8-2.2)$

$1.8(1.3-2.4)$

$1.0(0.8-1.5)$

$1.2(1.0-1.5)$

NS

$1.0(0.8-1.3)$

$2.8(1.5-5.4)$

1.0

NS: Not significant. NT: Not tested in multivariate model ( $p>0.20$ in univariate model).

$1.8(1.5-2.1)$

$0.9(0.7-1.1)$

$1.5(1.1-2.0)$

$0.6(0.3-1.2)$

NT

NT

NT

1.9 (1.4-2.6)

$0.5(0.3-0.8)$

$2.0(1.4-2.8)$

$0.8(0.5-1.3)$

NS

$2.7(1.8-4.2)$

NS

1.0

$1.1(0.7-1.7)$

3.7 (2.3-6.0)

$1.2(0.7-2.0)$

$1.9(1.5-2.3)$

1.0

1.0

1.0

2.9 (2.5-3.3)

2.3 (1.7-3.1)

1.9 (1.4-2.6)

$1.3(1.0-1.6)$

$2.1(1.5-3.2)$

\footnotetext{
In bold: significant $(p<0.01)$; due to rounding into 1 decimal 1.0 is not always significant.
} 
Table 3 Multivariate regression analyses for any STI and per STI in MSM aged 25 or older visiting STI clinics, the Netherlands, 2006-2012

\begin{tabular}{|c|c|c|c|c|c|}
\hline & $\begin{array}{r}\text { Any STI } \\
\text { OR }(95 \% \mathrm{Cl}) \\
\end{array}$ & $\begin{array}{r}\text { Chlamydia } \\
\text { OR (95\% CI) }\end{array}$ & $\begin{array}{l}\text { Gonorrhoea } \\
\text { OR }(95 \% \mathrm{CI})\end{array}$ & $\begin{array}{r}\text { Infectious syphilis } \\
\text { OR }(95 \% \mathrm{Cl})\end{array}$ & $\begin{array}{r}\text { HIV } \\
\text { OR }(95 \% \mathrm{Cl}) \\
\end{array}$ \\
\hline Year of consult & $0.97(0.95-0.98$ & NS & NS & $0.8(0.8-0.9)$ & $0.8(0.8-0.9)$ \\
\hline \multicolumn{6}{|l|}{ Age, years } \\
\hline 25-34 & 1.0 & 1.0 & 1.0 & 1.0 & NS \\
\hline $35-44$ & $0.9(0.9-1.0)$ & $0.9(0.9-1.0)$ & $0.9(0.8-0.9)$ & $1.3(1.2-1.4)$ & \\
\hline $45-54$ & $0.9(0.8-0.9)$ & $0.9(0.8-0.9)$ & $0.7(0.6-0.7)$ & $1.6(1.4-1.8)$ & \\
\hline$>54$ & $0.7(0.6-0.7)$ & $0.8(0.7-0.8)$ & $0.5(0.4-0.5)$ & $1.5(1.2-1.7)$ & \\
\hline \multicolumn{6}{|l|}{ Sexual behaviour } \\
\hline Sex with both men and women & 1.0 & 1.0 & 1.0 & 1.0 & 1.0 \\
\hline Sex with men only & $1.5(1.4-1.6)$ & $1.3(1.2-1.4)$ & $1.7(1.5-1.8)$ & $1.5(1.3-1.7)$ & $2.0(1.7-2.4)$ \\
\hline \multicolumn{6}{|l|}{ Ethnicity } \\
\hline Dutch & 1.0 & 1.0 & 1.0 & 1.0 & 1.0 \\
\hline Surinam/Antilles & $1.5(1.3-1.6)$ & $1.2(1.1-1.4)$ & $1.3(1.1-1.5)$ & $2.0(1.6-2.5)$ & $2.3(1.9-2.9)$ \\
\hline Turkey/Morocco & $1.2(1.1-1.4)$ & $1.2(1.0-1.5)$ & $1.3(1.1-1.5)$ & $1.1(0.7-1.7)$ & $1.4(1.0-2.0)$ \\
\hline Eastern Europe & $1.3(1.1-1.4)$ & $1.1(0.9-1.3)$ & $1.2(1.0-1.4)$ & $1.0(0.7-1.6)$ & $2.2(1.7-2.9)$ \\
\hline SS Africa & $1.6(1.3-2.0)$ & $1.4(1.0-1.9)$ & $1.4(1.0-1.9)$ & $1.0(0.5-1.9)$ & $3.8(2.5-5.7)$ \\
\hline Latin America & $1.3(1.1-1.4)$ & $1.0(0.9-1.2)$ & $1.1(1.0-1.3)$ & $1.7(1.3-2.2)$ & $2.7(2.1-3.4)$ \\
\hline Asia & $1.3(1.2-1.4)$ & $1.3(1.1-1.4)$ & $1.2(1.0-1.4)$ & $1.3(1.0-1.7)$ & $1.5(1.2-1.9)$ \\
\hline Other & $1.0(1.0-1.1)$ & $0.9(0.8-1.0)$ & $1.0(1.0-1.1)$ & $1.0(0.9-1.2)$ & $1.4(1.2-1.6)$ \\
\hline \multicolumn{6}{|l|}{ Previous HIV test } \\
\hline No & 1.0 & 1.0 & 1.0 & 1.0 & 1.0 \\
\hline Yes, negative & $0.8(0.8-0.8)$ & $0.8(0.7-0.9)$ & $0.9(0.8-1.0)$ & $0.7(0.6-0.7)$ & $0.6(0.5-0.7)$ \\
\hline Unknown & $0.8(0.7-0.9)$ & $0.8(0.6-0.9)$ & $0.8(0.6-0.9)$ & $1.0(0.8-1.4)$ & $1.2(0.9-1.5)$ \\
\hline \multicolumn{6}{|l|}{ Previous STI } \\
\hline No & 1.0 & 1.0 & 1.0 & 1.0 & 1.0 \\
\hline Yes & $1.7(1.6-1.7)$ & $1.5(1.4-1.6)$ & $1.6(1.5-1.8)$ & $1.5(1.3-1.7)$ & $2.0(1.4-2.8)$ \\
\hline Unknown & $1.0(0.9-1.1)$ & $1.0(0.9-1.1)$ & $1.1(1.0-1.3)$ & $0.8(0.7-1.0)$ & $0.9(0.5-1.4)$ \\
\hline \multicolumn{6}{|l|}{ CSW } \\
\hline No & 1.0 & NS & 1.0 & NT & NS \\
\hline Yes, in $<6$ months & $0.8(0.7-0.9)$ & & $0.8(0.6-0.9)$ & & \\
\hline Unknown & $0.4(0.3-0.6)$ & & $0.3(0.1-0.5)$ & & \\
\hline \multicolumn{6}{|l|}{ Client of CSW } \\
\hline No & 1.0 & 1.0 & 1.0 & NS & NS \\
\hline Yes, in $<6$ months & $0.6(0.5-0.7)$ & $0.7(0.5-0.8)$ & $0.6(0.5-0.8)$ & & \\
\hline Unknown & $1.4(1.0-2.1)$ & $0.7(0.5-0.9)$ & $1.7(0.9-3.2)$ & & \\
\hline \multicolumn{6}{|l|}{ No of partners in $<6$ months } \\
\hline $0-1$ & 1.0 & 1.0 & 1.0 & 1.0 & 1.0 \\
\hline $2-10$ & $1.5(1.4-1.6)$ & $1.5(1.3-1.6)$ & $1.8(1.6-2.0)$ & $0.9(0.7-1.0)$ & $1.3(1.1-1.5)$ \\
\hline$>10$ & $1.9(1.8-2.1)$ & $1.7(1.6-1.9)$ & $2.4(2.1-2.7)$ & $0.9(0.7-1.1)$ & $1.7(1.4-2.1)$ \\
\hline Unknown & $1.6(1.5-1.7)$ & $1.5(1.4-1.7)$ & $1.9(1.7-2.2)$ & $0.7(0.6-0.9)$ & $1.3(1.1-1.6)$ \\
\hline
\end{tabular}




\begin{tabular}{|c|c|c|c|c|c|}
\hline \multicolumn{6}{|l|}{ Notified } \\
\hline No & 1.0 & 1.0 & 1.0 & 1.0 & 1.0 \\
\hline Yes & $2.2(2.1-2.3)$ & $1.9(1.8-2.1)$ & $2.3(2.1-2.4)$ & $1.9(1.6-2.1)$ & $2.2(1.9-2.4)$ \\
\hline Unknown & $1.1(1.0-1.2)$ & $1.0(1.0-1.1)$ & $1.3(1.1-1.4)$ & $1.2(1.0-1.4)$ & $0.8(0.7-1.0)$ \\
\hline
\end{tabular}

NS: Not significant. NT: Not tested in multivariate model ( $p>0.20$ in univariate model). In bold: significant $(p<0.01)$; due to rounding into 1 decimal 1.0 is not always significant.

Among MSM younger than 25 years, Surinamese and Latin American backgrounds were stronger associated with testing positive for an STI, as well as the number of sexual partners and being notified for an STI, compared to older MSM. Young MSM involved in CSW also tested more often positive than those not involved in CSW, but no such effect was observed among older MSM. Having a previous HIV test was protective among older MSM, but not among younger MSM.

The increasing and high STI positivity rates in young MSM are cause for great concern. This is mainly driven by persistently high positivity rates for chlamydia and an increasing positivity rate for gonorrhoea. The latter is especially worrisome with regard to the increasing problem of antimicrobial resistance with the risk of gonorrhoea becoming untreatable [13].

Special attention needs to be paid towards counselling of sexually risk taking in young MSM, since adolescents and young adults are exploring their sexuality and disclosure regarding sexual identity and sexual behaviour may be limited [14]. Young MSM use the internet and social media among others to search for sex partners and for information regarding safe sex and STI [15]. This provides us with the opportunity of developing new web-based and multi-media interventions for prevention in order to reach young MSM. The effective use of such new media in establishing new prevention activities, including e-health interventions or placing banners and STI information on websites or other online media which are frequently used by MSM needs to be explored and the effectiveness of such interventions should be assessed.

Current data show that non-Dutch MSM in both age groups are also at high-risk testing positive for an STI. A recent Dutch survey pointed out that young migrant MSM are hardly reached by current prevention and intervention programmes [15]. Current HIV and STI prevention programs targeted at migrant MSM should be strengthened to increase their awareness of and knowledge on STI, in particular around HIV, and reduce stigma around homosexuality. In addition, 'mainstream' interventions focused at reaching MSM should be culturally sensitive to attract a broader audience.
The current study shows that within the population of young MSM, those involved in commercial sex were at significantly higher risk for testing positive for an STI than those not involved. Although the group of MSM visiting an STI clinic who are involved in CSW is only a small group, targeted health education to encourage safer sex work is needed to improve both the health of the sex workers and their clients. This is important since sex workers have many (unsafe) sexual contacts and therefore STIs can be transmitted more quickly. Little is known about the determinants of (un)safe sex of MSM involved in commercial sex and research on this would be necessary in order to develop effective interventions targeted at this specific group.

The loss of fear regarding HIV transmission due to better treatment options for HIV infection by combination antiretroviral therapy (cART) may play a role in the explanation for the persistent high rates of STI in especially young MSM and the outcome that no protective effect of previous HIV testing was found in young MSM [16-18]. The so-called 'post-aids generation' did not experience the dying, multiple losses and fear for infection during the first decennia of the HIV epidemic. Stolte et al. [18] report an increase in MSM attending STI clinics and a rise in infection rates coinciding with the introduction of cART. Data from an online survey among Dutch MSM showed a significant increase in unprotected anal intercourse with a casual partner from $33 \%$ in 2009 to $36 \%$ in 2011 [15], indicating high-risk behaviour. Since 2011, condom use with the last sex partner (casual or steady) is registered for all STI clinic attendees. In both age groups, 61\% of MSM reported not having used a condom during their last sexual contact with a casual partner (data not shown).

Our study included only data from STI clinics and extrapolation to the general population and MSM community should be done with caution, since the STI clinics are facilities set up for high risk groups, in addition to regular primary health care. Most people in the Netherlands consult their general practitioner (GP) for STI testing $[19,20]$. However, two recent Dutch studies comparing data from GPs with STI clinics, showed that STI clinic visitors are more often from high-risk groups, 
like MSM [20,21]. Trienekens et al. showed that only $9 \%$ of consultations in GPs concerned MSM, compared to more than one third in STI clinics [21]. Also, results from a recent survey (2011) in the Netherlands showed that of the MSM who were tested for HIV in the past six months, $60 \%$ was tested at an STI clinic, compared to $28 \%$ at their GP [15]. These results suggest that MSM who want to get tested perceived a low threshold to access STI clinics. Another limitation of current study is that no information is available about the unique number of MSM attending the STI clinics, but only about the number of consultations in MSM. This might influence the different outcomes.

\section{Conclusion}

In conclusion, MSM visiting STI clinics remain a highrisk group for STI infections and transmission, but are not a homogenous risk group. While in MSM aged older than 25 years, STI positivity is decreasing, a significant increase in positivity rate was found in young MSM. Special sub-groups, like young migrant MSM and young MSM sex workers, do also need to be targeted specifically to prevent further transmission of STI.

\section{Key messages}

- MSM visiting STI clinics remain a high-risk group

- An increase in STI positivity rate was found in young MSM

- Counselling and reaching specific MSM sub-groups at highest and increasing risk remains very important

\section{Additional file}

Additional file 1: Table S1. Results for the univariate regression analyses for any STI and in consultations in young MSM (<25 years) and older MSM ( $\geq 25$ years) visiting STI clinics, the Netherlands, 2006-2012.

Table S1 is presenting the univariate odds ratios (ORs) for the associoation between variables included in the study and the outcome of having any STI. Results are presented separately for young MSM ( $<25$ years) and older MSM ( $\geq 25$ years) who visited an STI clinic in the Netherlands between 2006 and 2012.

\section{Competing interests}

The authors declare that they have no competing interests.

\section{Authors' contributions}

The study was designed by FK, BB, EV, WZ and MS. BB and MS supervised data analysis. FKB analysed the data and wrote the first draft of the article. All authors read and approved the final manuscript.

\section{Authors' information}

Dutch STI clinics: A van Daal (East), AP van Leeuwen (North-Holland Flevoland), F. de Groot (North), CJPA Hoebe (Limburg), K Hulshof (Utrecht), A van Camerijk (South-Holland North), JCAM van de Sande (Zeeland-Brabant), V Wieërs (South-Holland South).

\section{Acknowledgement}

We thank all Public Health nurses and physicians of the STI clinics for their contribution in data collection and medical microbiology laboratories for STI diagnostics.

\section{Author details}

${ }^{1}$ Centre for Infectious Disease Control, RIVM National Institute of Public Health and the Environment, P.O. Box 1, 3720 BA Bilthoven, Utrecht, The Netherlands. ${ }^{2}$ Municipal Health Service Twente, Enschede, The Netherlands. ${ }^{3}$ STI AIDS Netherlands, Amsterdam, The Netherlands. ${ }^{4}$ Julius Center for Health Sciences and Primary Care, University Medical Centre Utrecht, Utrecht, The Netherlands.

Received: 13 June 2014 Accepted: 1 August 2014

Published: 28 August 2014

\section{References}

1. Soetens LC, Koedijk FDH, van den Broek IVF, Vriend HJ, Op de Coul ELM, van Aar F, van Sighem Al, Stirbu-Wagner L, van Benthem BHB: Sexually Transmitted Infections, including HIV, in the Netherlands in 2012. Bilthoven: Centre for Infectious Disease Control - National Institute for Public Health and the Environment (RIVM); 2013.

2. Centers for Disease Control and Prevention (CDC): Sexually Transmitted Diseases (STDs). Secondary Sexually Transmitted Diseases (STDs) April 26, 2013 2013. http://www.cdc.gov/std/sam/.

3. de Graaf H: Seksueel gedrag en seksuele beleving in Nederland. Tijdschrift voor Seksuologie 2012, 36(2):87-97.

4. Dean L, Meyer I: HIV prevalence and sexual behavior in a cohort of New York City gay men (aged 18-24). J Acquir Immune Defic Syndr Hum Retrovirol 1995, 8(2):208-211.

5. Lemp GF, Hirozawa AM, Givertz D, Nieri GN, Anderson L, Lindegren ML, Janssen RS, Katz M: Seroprevalence of HIV and risk behaviors among young homosexual and bisexual men. The San Francisco/Berkeley Young Men's Survey. JAMA 1994, 272(6):449-454.

6. Osmond DH, Page K, Wiley J, Garrett K, Sheppard HW, Moss AR, Schrager L, Winkelstein W: HIV infection in homosexual and bisexual men 18 to 29 years of age: the San Francisco Young Men's Health Study. Am J Public Health 1994, 84(12):1933-1937.

7. Janiec J, Haar K, Spiteri G, Likatavicius G, van de Laar M, Amato-Gauci AJ: Surveillance of human immunodeficiency virus suggests that younger men who have sex with men are at higher risk of infection, European Union, 2003 to 2012. Euro Surveill 2013, 18(48):20644.

8. Mansergh G, Marks G: Age and risk of HIV infection in men who have sex with men. AIDS 1998, 12(10):1119-1128.

9. Dosekun O, Fox J: An overview of the relative risks of different sexual behaviours on HIV transmission. Curr Opin HIV AIDS 2010, 5(4):291-297. doi:10.1097/COH.0b013e32833a88a3 [published Online First: Epub Date]|.

10. Rowniak S: Safe sex fatigue, treatment optimism, and serosorting: new challenges to HIV prevention among men who have sex with men. J Assoc Nurses AIDS Care 2009, 20(1):31-38. doi:10.1016/j.jana.2008.09.006 [published Online First: Epub Date]|.

11. Op de Coul E, Warning T, Koedijk F, Dutch STI clinics: Sexual behaviour and sexually transmitted infections in sexually transmitted infection clinic attendees in the Netherlands, 2007-2011. Int J STD AIDS 2014, 25(1):40-51. doi:10.1177/0956462413491736[published Online First: Epub Date]|

12. Nederlandse Vereniging voor Dermatologie en Venereologie: Multidisciplinaire Richtlijn Seksueel Overdraagbare Aandoeningen voor de 2e Lijn. http://soaaids.nl/nl/professionals/beroepsgroep/arts/ professioneel-handelen/de-specialist.

13. Unemo M, Ison CA, Cole M, Spiteri G, van de Laar M, Khotenashvili L: Gonorrhoea and gonococcal antimicrobial resistance surveillance networks in the WHO European Region, including the independent countries of the former Soviet Union. Sex Transm Infect 2013, 89(Suppl 4): iv42-iv46. doi:10.1136/sextrans-2012-050909 [published Online First: Epub Date]|.

14. Savin-Williams RC, Ream GL: Prevalence and stability of sexual orientation components during adolescence and young adulthood. Arch Sex Behav 2007, 36(3):385-394. doi:10.1007/s10508-006-9088-5 [published Online First: Epub Date]|

15. van Empelen P, van Berkel M, Roos E, Zuilhof W: Schorer Monitor 2011. Amsterdam: Schorerstichting; 2011. 
16. Kelly JA, Hoffman RG, Rompa D, Gray M: Protease inhibitor combination therapies and perceptions of gay men regarding AIDS severity and the need to maintain safer sex. AIDS 1998, 12(10):F91-F95.

17. van der Snoek EM, de Wit JB, Mulder PG, van der Meijden WI: Incidence of sexually transmitted diseases and HIV infection related to perceived HIV/ AIDS threat since highly active antiretroviral therapy availability in men who have sex with men. Sex Transm Dis 2005, 32(3):170-175.

18. Stolte IG, Dukers NHTM, de Wit JBF, Fennema JS, Coutinho RA: Increase in sexually transmitted infections among homosexual men in Amsterdam in relation to HAART. Sex Transm Infect 2001, 77(3):184-186. doi:10.1136/ sti.77.3.184 [published Online First: Epub Date].

19. van Bergen JE, Kerssens JJ, Schellevis FG, Sandfort TG, Coenen TJ, Bindels PJ: Prevalence of STI related consultations in general practice: results from the second Dutch National Survey of General Practice. Br J Gen Pract 2006, 56(523):104-109.

20. van den Broek IV, Verheij RA, van Dijk CE, Koedijk FD, van der Sande MA, van Bergen JE: Trends in sexually transmitted infections in the Netherlands, combining surveillance data from general practices and sexually transmitted infection centers. BMC Fam Pract 2010, 11:39. doi:10.1186/14712296-11-39 [published Online First: Epub Date]|.

21. Trienekens SC, van den Broek IV, Donker GA, van Bergen JE, van der Sande MA: Consultations for sexually transmitted infections in the general practice in the Netherlands: an opportunity to improve STI/HIV testing. BMJ Open 2013, 3(12):e003687. doi:10.1136/bmjopen-2013-003687 [published Online First: Epub Date]|

doi:10.1186/1742-7622-11-12

Cite this article as: Koedijk et al: Increasing sexually transmitted

infection rates in young men having sex with men in the Netherlands, 2006-2012. Emerging Themes in Epidemiology 2014 11:12

\section{Submit your next manuscript to BioMed Central and take full advantage of:}

- Convenient online submission

- Thorough peer review

- No space constraints or color figure charges

- Immediate publication on acceptance

- Inclusion in PubMed, CAS, Scopus and Google Scholar

- Research which is freely available for redistribution 